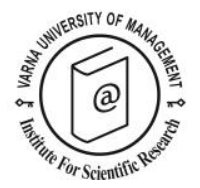

\title{
Study abroad:
}

\section{the influence of city and university attractiveness factors}

\author{
Liliana Moreira $^{1^{*}}$ and Rui Machado Gomes ${ }^{2}$
}

Received: 02/08/2017 Accepted: 16/12/2018

\footnotetext{
${ }^{1}$ Faculty of Sport Sciences and Physical Education, University of Coimbra; email: liliana@fcdef.uc.pt

${ }^{2}$ Centre for Social Studies, Associated Laboratory, University of Coimbra

* Corresponding author
}

Coordinating editor: Stanislav Ivanov

\begin{abstract}
This article aims to analyse the motivational factors, which influence students to study abroad, taking as a case study the student flows directed to the University of Coimbra in Portugal and the University of Groningen in Netherlands. The theoretical framework is complemented by a push-pull factors model of both cities and universities. The paper uses a quantitative approach based in a questionnaire survey of a sample of 507 students. The motives for studying abroad are different according to University and type of student registration. There are no significant differences between attractiveness factors of the two cities but there are significant differences when the global indexes of attractiveness of the universities are compared. This data provides empirical evidence that can be used by higher education institutions, local and central governments in the development of educational and touristic strategies.
\end{abstract}

Keywords: international student, scholar mobility, educational tourism, higher education

Citation: Moreira, L., R. Gomes (2019) Study abroad: the influence of city and university attractiveness factors. European Journal of Tourism Research 22, pp. 79-93

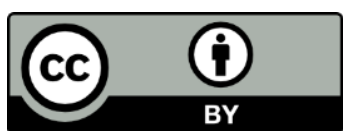

RESEARCH PAPER
This work is licensed under the Creative Commons Attribution 4.0 International (CC BY 4.0). To view a copy of this license, visit https://creativecommons.org/licenses/by/4.0/ 


\section{Introduction}

One of the most striking phenomena today is movement of people, in mass, from all ages and to multiple destinations. These mobilities are influenced by the processes of globalization (Giddens, 1999, Urry, 2007). The growing flow of people in cross-border movements brings us to a new way of understanding mobility, defined by Appadurai (1994) as ethnoscape. Mobility is associated with deterritorialization, outside the traditional concepts of territory, frontier and sovereignty. Zygmunt Bauman even refers to "dephysicalization" (Bauman, 1988, p.19), where distance is a social product that varies according to the speed of communication. Mobilities are a renewed object of study of social sciences that contribute to a new paradigm:

\section{"...this paradigm examines how social relations necessitate the intermittent and intersecting movements of people, objects, information and images across distance. It has been shown how social science needs to reflect, capture, simulate and interrogate such movement across variable distances. This paradigm forces us to attend to this economic, social, and cultural organization of distance, and not just to the physical aspects of movement." (Urry, 2007, p. 54).}

One of these movements is performed by international students, identified by UNESCO as "students that leave their country or territory of origin and move to another country or territory with the objective of studying" (UNESCO, 2009, p. 36).

In fact, the current relevance of this study is justified by the actual worldwide movement of students. The global movement "rising from 2 million in 1999 to 5 million 17 years later in the OECD area" (OECD, 2016, p. 219). These numbers reinforce the globalization of mobility and allow us to understand the growing importance that Governments and higher education institutions give to capturing this new segment of education market consumers (Moreira \& Gomes, 2017).
In this study, there are two categories of international university students: the student who wants to get the diploma by the host university and remains longer than a year, defined as regular; and the student in shorter time stays without the purpose of obtaining a diploma, the mobility student.

The regular international student is defined by Glover:

"Independent of their consecutive length of stay, international students may be classified as temporary residents in their study destination due to their extend stay. This temporary residence may stretch over several years, for example, when students undertake a full degree or enrol in a second degree after finishing their first." (Glover, 2011, p. 181).

In 1950, the International Union of Official Travel Organizations, the precedent of the World Tourism Organization, incorporated education into the motivations of tourists. This motivation allows us to understand the mobility international student. Nowadays, the educational tourist is understood as the temporary visitor moving across borders, for a period exceeding 24 hours, whose purpose of travel is a learning mission.

This paper aims to contribute to the knowledge of the motivational factors, that influence students to study abroad with the aim of learning in the context of mobility or the obtaining of a diploma. For that purpose, this study sought to investigate the gathering of factors influencing the mobility of international students comparing foreign students at the Universities of Coimbra and Groningen, two European higher education institutions in two medium sized cities.

The choice of the cities of Coimbra in Portugal and Groningen in the Netherlands was established on the basis of the theory of worldsystems and world-economies (Wallerstein, 1991). In this geo-economic context, countries are divided by their production, capital and labour. This theory has some variations, but within the European framework, Netherlands is referred as a central country and Portugal as a semi-peripheral country. 
The study of international student flow is carried out, not only in an individual subjectactor logic, as a student and a tourist, but also seeks to contextualize the action in the cities dynamics. For this purpose, three major goals were chosen, according to push-pull theories. The goals will allow us to answer the starting question what motivates a foreign student to enrol in a foreign university in a European medium-sized city, located in a different country that is not his permanent residence?

The first goal was to identify the motives to study abroad, taking into consideration the listing of factors influencing the choice of nonpermanence in the country of origin, that is, the push factors, in the economic, political and educational sphere. Namely, the existence of a university network or the absence of the desired educational field of specialization. The second goal, was to determine the influence of structural factors of university education in attracting education tourism, the appealing factors were identified based on the following spheres: geographic, economic, educational, image, cultural, political and administrative. The third goal was to determine the influence of structural factors of each city, in the student choice.

This paper is structured in the following sections: the introduction where the importance of the theme and the goals are explained followed by the literature review. The empirical settings where both higher education institutions are presented. The methodology section presents the sample, the pilot study and the empirical research instrument. The results section integrates the data analysis, including the creation of two global attractiveness indexes, for the city and the university followed by the section of discussion. At the end, the paper presents the contributions, limitations and future research directions.

\section{Literature review}

Foreign education consumption

Regarding academic travel, Barnett and Phipps cited by Chen (2017a) indicate how to observe the phenomenon of educational tourism:
"Conceptualized academic mobility from travel literature that speaks to the spatial and temporal dimensions of travelling and travelers. They analyzed academic travel into three forms: geographical, where academics as bodies move in space...; epistemological, where academics move into new knowledge homes and ontological, where the academic takes a new or a widened sense of herself. They believed these three forms intersect each other." (Chen, 2017b, p. 36).

From the perspective of foreign education consumption, international students, as educational tourists, follow the migration flows from peripheral countries to the central and semi-peripheral countries, according to the world-system theory. In historical terms, the movement is done from developing countries to developed countries. Within this logic, the hegemonic effect of globalization spreads. The relations among nations are established by power status that are different and unequal, according to the world system theory. The coding of countries is usually done by their position in the world system with economic assumptions. In fact, studies

\section{“...found a negative correlation between economic prosperity in sending countries and the volume of international students flows, perhaps because greater educational opportunity counteracts the effect of improved GDP per capita ... a positive correlation was found between the size of host nation and the sending nation's economies." (Mazzarol \& Soutar, 2001, p. 4)}

The results of several studies suggest that we go into a transnational sphere of commercial university services where the consumption of education abroad fits in the typology of services of the World Trade Organization and consists in providing the service through consumer transnational movement. This is currently the major share of commercial transnationalisation of the University (Santos, 2005). Academic internationalization is one of the means through which revenue can be generated in an effort to offset financial concerns of the institution 
(Chen, 2017b, p.120). As an example of the revenue, in the United Kingdom, the HESA (Higher Education Statistics Agency) shows that "more recent statistics would suggest this figure has significantly increased and considers the value of educational services to currently stand at $£ 10.3$ billion" (Barron, Baum \& Conway, 2007, p. 88).

The demand for higher education has changed, it has become transnational. Nowadays, it is usual that the demand for a diploma abroad or for a mobility period abroad will bring an added value to the curriculum vitae (Tarrant et al., 2011; Chao et al., 2017). People seek transnationally what they cannot find within borders such as new fields of knowledge and greater recognition, in short, a new optimistic view of education that allows security and social mobility. Barron, Baum and Conway states that some students consider the diploma they get abroad as more important the one obtained within boarders: "... learning, living and working experience that is a major financial and time investment in the future of both individuals and society at large" (2007, p. 97). Studying abroad has become a personal investment.

The institutions adapted their policies to this consumption of education abroad (Gardiner, King \& Wilkins, 2013). The countries that come at the top as host countries - USA, UK and Australia - are referred to, not only because of the English language, but also due to their ability to adjust in bureaucratic terms and consular visa requirements, "various developments have shown that international student and graduate visa schemes are increasingly used as integral parts of recruitment strategies and are receiving more attention in accordance with their perceived importance and strategic value" (Verbik \& Lasanowski, 2007, p. 24).

\section{A new approach to the worldwide movement of students}

In the mass demand for international education, something is changing globally, with the growth of new financial initiatives in some countries, different geopolitical motivations, students choosing non-traditional destinations, the students' retention policies in traditionally sending countries, this way changing the very objects of study as flows of international students (Bhandari \& Blumenthal, 2011). Additionally, new actors appeared, such as forprofit or non-profit organisations, which can work as driving elements of this market segment. There are indicators, some counterhegemonic directions, however small, to combat student movement from south to north (Jaramillo \& Wit, 2011).

There are countries that although they have a matrix of receivers, countries that host more students than they send, and so wish to continue, recognize the added value of internationalisation to the nationals of their countries, due to the enormous advantages of dialogue among cultures, and for this reason they promote mobility practices, such as the philosophy of DAAD in Germany.

In future, we will find a new way of understanding the worldwide movement of students, a new paradigm that

"(...) include the concept of
internationalization itself, the notion of
global citizenship, varieties of global
engagement, the impact of technology
on internationalization (e.g., the notion of
virtual mobility), new dimensions in study
abroad, and the role of
internationalization in the broader higher
education field." (Deardorff, de Wit \&
Heyl, 2012, p. 457)

The perspective of the transnationalisation of education can be complemented by the analysis model of push-pull factors that influence the mobility decision, at the micro level (Hattie et al., 1997; Eder, Smith \& Pitts, 2010; Michael, Armstrong \& King, 2003; Chen, 2017b). This idea follows on from some authors who argue that the education tourism model can be subdivided into students who privilege academic reasons (Ritchie, 2003) or students who give priority to touristic motives (Hattie et al., 1997). Llewellyn-Smith \& McCabe contend that Australia is selected "as a host destination because of the travel and tourism-related opportunities, such as 'sea, sun and surf', 'tourist and cultural attractions available' and 'scenery and natural environment', as opposed 
to any education related 'pull' factors offered by the host university" (2008, p. 604).

In contrast, Mazzarol \& Soutar (2001) argued that "quality of reputation is likely to remain the most important factor influencing study destination choice. This is unsurprising, but highlights the need for host country governments to invest in education to ensure quality is maintained" (Mazzarol \& Soutar, 2001, p. 13). Following the same reasoning, Eder, Smith \& Pitts (2010) proposed that the critical factors to choose the United States "as the final destination included: (1) Englishspeaking country; (2) the availability of courses and departments; and (3) the location" (p. 147). As Glover (2011) points, "universities cannot rely solely on promoting their academic benefits but need to publicize other advantages of choosing the institution and destination for overseas study" (Glover, 2011 p. 191).

Glover (2011) studied the motivations for studying abroad, relating them to the image of the target places. "The findings are interpreted in a conceptual framework which combines information sources, destination image, and decision-making regarding study and tourism activities" (Glover, 2011, p. 181). The target image is intersected by tourism (Gallarza, Saura \& Garcia, 2002), the academic field and general recommendations, guiding students to tourism or education (Glover, 2011). In sum, "understanding education decisions therefore and linking tourism choices with education choices appears to be a viable strategy for the tourism industry seeking new opportunities to attract tourists" (Michael, Armstrong \& King, 2003, p. 64).

In the current study, the motivations for studying abroad are explored within two universities and two medium size cities, Groningen and Coimbra.

\section{Empirical setting}

The choice of the cities of Groningen and Coimbra cities and their universities was deliberate and intended to build a favourable context to compare international student flows between two medium-sized cities. Both universities have more than four centuries, Coimbra being the oldest, and both belong to common scientific cooperation networks, as Coimbra Group. This link allowed the contact between institutions and facilitated the collection of data.

There are some differences regarding to the educational offer between the institutions (Table 1).

Table 1. Institutional indicators

\begin{tabular}{lcc}
\hline & UC & RUG \\
\hline Number of $1^{\text {st }}$ cycle courses & 39 & 54 \\
Number of $2^{\text {nd }}$ cycle courses & 129 & 199 \\
Number of Ph.D. students & 2.385 & 1.500 \\
International students & 3688 & 4.303 \\
\hline Total number of students & 25.600 & 27.700 \\
\hline
\end{tabular}

We emphasize the fact that 91 second cycle courses from RUG being exclusively in the English language. Most of the international students come from neighbouring countries or countries with a colonial past related to Netherlands and Portugal, like Indonesia or Brazil respectively.

With an approximately equal number in total populations and, almost the same number of students and faculties, this study analysed the factors influencing the international mobility of students to the University of Coimbra, Portugal, and to the University of Groningen, the Netherlands.

\section{Methodology}

This paper combines a descriptive analysis providing the portrait of a group of international students and a correlation analysis establishing an association between variables based in the data analysis of questionnaires.

The comparative study required the creation of two independent samples identified in table 2 $(n=507)$, calculated based on a 95 per cent confidence level, obtained through a probabilistic method from the population of all international citizens to enrol at the University of Coimbra and at the University of Groningen. The proportional sampling technique allows to create two major strata: regular student and mobility student.

International students were divided into two major strata: regular (get their diploma from the 
host university) and mobility (get the diploma from the university of origin). The sample size was calculated based on a 95\% confidence level and a tolerance sampling error of 0.05 for Coimbra and 0.08 for Groningen.

Table 2. Sample characteristics

\begin{tabular}{llll}
\hline Regular students & UC & RUG & TOTAL \\
\hline $1^{\text {st }}$ cycle & 95 & 64 & 159 \\
$2^{\text {nd }}$ cycle & 88 & 33 & 121 \\
$3^{\text {rd }}$ cycle & 44 & 30 & 74 \\
Mobility students & & & \\
1st, 2nd cycle, 3rd cycle & 128 & 25 & 153 \\
\hline TOTAL & 355 & 152 & 507 \\
\hline
\end{tabular}

The data collection technique was the survey, appropriate to empirical research with quantitative data, addressed at international students in both universities, in Portuguese and English at the University of Coimbra, and only in English at the University of Groningen.

The pilot study allowed to determine the internal consistency of the questionnaire as pre-test $(n=65)$ through the estimation of internal reliability, understood as the measurement instrument capacity to give similar results when repeated measurements are carried out in similar testing conditions (Spata, 2005). In this case, the reliability was assessed through the application of the Cronbach's Alpha test, an indicator of homogeneity in tests applied for the first time, with a very strong indicator of internal consistency: Reasons for study abroad: $\alpha=0.831$; University attractiveness factors: $\alpha=0.931$; City attractiveness factors: $\alpha=0.911$. These results allowed us to apply the same questionnaire to the definitive sample.

The content validity was observed based on the reading of the extensive existing literature that identified the components of the latent variable in analysis, which enriched the work, and simultaneously increased the number of items per issue. The content's validity implies the degree of agreement among the results obtained in the test, theory and practice regarding the spheres in evaluation and hence the relevance of expression also used of hypothetical-deductive validity. According to
Black (1999), this kind of validity should combine a logical, statistical and empiric analysis. The first involves the correction of the wording of the items. The statistical approach was ensured by observing the reliability levels of the items.

The first section of the survey implied openended questions related to personal information. The second section asked the importance level given to reasons to study abroad based in the scientific literature (Hattie et al., 1997; Ritchie, 2003; Bhandari \& Blumenthal, 2011; Gallarza, Saura \& Garcia, 2002; Jaramillo \& Wit, 2011; Michael, Armstrong \& King, 2003; Mazzarol \& Soutar, 2001). It relates to one of the goals of identifying the country of origin push factors (eighteen items assessed). The response scale is an ordinal assessment by importance level, 1-5 point Likert scale. The Principal Component Analysis was applied to the survey items (Kline, 2002). Comparisons among institutions and enrolment situations were analysed through the T-Test for Difference in Means.

Two more questions measured the importance level of the structural factors of attraction of medium-sized cities (Chen, 2017a; Eder, Smith \& Pitts, 2010, Glover, 2011, Llewellyn-Smith \& McCabe, 2008) and universities (Glover, 2011, Barron, Baum \& Conway, 2007; LlewellynSmith \& McCabe, 2008). The response scales are ordinal assessments by importance level assigned to each item.

The items about the city's and university's attractiveness were object of a Principal Component Analysis. Thus, two global attractiveness indexes were created, one for the city and another for the university. These global indexes were originated on a new Principal Component Analysis with the components created by each attraction factor. Hence, it allowed us to compare, for each sample of Coimbra and Groningen, the crosschecking of the attractiveness global indexes.

\section{Results}

Reasons for studying abroad per University and per registration

Regular students are in greater number at the University of Groningen and this institution is 
the one, which charges more tuition fees. University Coimbra presents a larger number of mobility students.

The parents' educational level is higher for the Groningen students, both at the father and mother's level of education. It should be noted that the students choosing the Dutch university come mostly from central or semi-peripheral countries, like Germany and Belgium. In the case of the University of Coimbra, even the students in mobility programs come mostly from more European peripheral countries, like Poland. The origin of the students also confirmed the colonial background, Indonesia to Groningen and Brazil to Coimbra.

The study aimed at deepening the question of willingness to study abroad. This was a starting point for this line of research, but we wanted to go further and know the factors motivating citizens to travel abroad to study. More specifically, the reasons for studying abroad were measured on a response classification scale 1 "Not important" to 5" Very important", applied to 18 items, and are shown in Table 3. On a response classification scale of 5 points, the importance given to the reasons appears in 15 items with an average above 3 in Coimbra and in17 items above 3 in Groningen.

To understand the reasons to study abroad, the results were subject to an exploratory analysis with the Principal Component Analysis method, thus validating the adequacy of the sample (by the Kaiser-Meyer-Olkin's test $\mathrm{KMO}=0.819$, confirmed by the significant value of the chisquare presented in the Bartlett's test with a $p<0.05)$. There were five factors under analysis, with the Kaiser criterion of eigenvalues above 1 that explain the correlations among the variables, explaining 62 per cent of total variance. Thus, Table 3 presents the items composing the factors and their internal consistency.

The last two components from factor 5 : migratory of table 3 do not represent such a

Table 3. Reasons for studying abroad

\begin{tabular}{|c|c|c|c|c|}
\hline & $\begin{array}{c}\text { Factor } \\
\text { loading }\end{array}$ & $\begin{array}{c}\text { Cronbach's } \\
\text { Alpha }\end{array}$ & $\begin{array}{c}\text { Eigenva } \\
\text { lues }\end{array}$ & $\begin{array}{c}\text { Variance } \\
\text { explained }\end{array}$ \\
\hline FACTOR 1: Economic & & 0.821 & 4.331 & $24.06 \%$ \\
\hline Raise their income in the future & 0.847 & & & \\
\hline Valorization of a foreign diploma in the country of origin & 0.808 & & & \\
\hline New perspectives of employability & 0.797 & & & \\
\hline Assure a high social status & 0.743 & & & \\
\hline Contribute for the economic development of their country & 0.620 & & & \\
\hline Personal valorisation & 0.390 & & & \\
\hline FACTOR 2: Social & & 0.764 & 3.110 & $17.27 \%$ \\
\hline Experience living in a different country & 0.843 & & & \\
\hline Craving for travelling & 0.786 & & & \\
\hline Establish new friendships & 0.626 & & & \\
\hline Spirit of adventure & 0.598 & & & \\
\hline FACTOR 3: Personal & & 0.772 & 1.612 & $8.95 \%$ \\
\hline Be autonomous & 0.815 & & & \\
\hline Learn problem-solving & 0.767 & & & \\
\hline Experience living without the parents & 0.756 & & & \\
\hline FACTOR 4: Academic & & 0.419 & 1.098 & $6.09 \%$ \\
\hline Interest on the Study Plan & 0.744 & & & \\
\hline Develop language skills & 0.633 & & & \\
\hline Non-existence of the study field in the country of origin & 0.461 & & & \\
\hline FACTOR 5: Migratory & & 0.484 & 1.026 & $5.70 \%$ \\
\hline Know the country of their ancestors & 0.772 & & & \\
\hline Aim at obtaining a permanent residence visa & 0.688 & & & \\
\hline Total variance explained & & & & $62.09 \%$ \\
\hline
\end{tabular}


consistent internal reliability. However, they present an eigenvalue above one and according to Carvalho (2004), when two items are correlated with a factor, it will only be accepted and consequently to its interpretation, if the correlation between the two variables is higher between them $(>0.70)$ and if the correlation with the remaining factors is weak (Carvalho, 2004, p. 149).

Table 4, with the t-test for difference in means per university, shows that the averages of the reasons for studying abroad are different to students from Coimbra and Groningen $($ sig<0.05), namely the economic and academic reasons, but are similar in the social (in this case, not too significant), personal and migratory ones.

By observing the data in table 4 economic reasons are not one of the main motives for the Groningen students. The average cost of living in the Netherlands is higher than the one in Portugal, so it is possible to conclude that students who can afford the costs in a central country may have fewer concerns in that area. On the other hand, economic reasons are a factor to which the UC students devote their attention, since they present a result above average. Such data reveals the economic capital of the sample students.
The inverse situation occurs with academic reasons: the RUG students register values above average, a situation contrasting with the UC students, with a register below average. According to results, RUG concentrates regular students, the group who prioritises "study first" (Glover, 2011 and Llewellyn-Smith \& McCabe, 2008). RUG students are more influenced by social reasons, although, in this field, both samples register average results. In conclusion, for decision-making about studying abroad, these students present different reasons, in what concerns economic and academic reasons.

In the case of the economic reasons in the items: assuring a higher social status, contributing for the economic development of the country of origin; valorisation of a foreign diploma in the country of origin. These reasons are specific to students coming from semiperipheral and peripheral countries and mirror the enchanted search for education (Gomes, 2005), according to other authors who equally call the attention to the fact that obtaining a diploma abroad corresponds to an investment (Barron, Baum \& Conway, 2007).

Regarding social motives, the items such as spirit of adventure and craving for travelling are

Table 4. T-test for equality of means: motives for studying abroad per university

\begin{tabular}{lllll}
\hline & \multicolumn{2}{l}{$\begin{array}{l}\text { Averages for } \\
\text { standardized values }\end{array}$} & $\begin{array}{l}\text { t-test for Equality of } \\
\text { Means }\end{array}$ \\
\cline { 2 - 5 } & UC & RUG & t & $\mathbf{p}$ \\
\hline Economic motives & 0.096 & -0.224 & 3.334 & 0.001 \\
Social motives & 0.120 & -0.051 & -1.860 & 0.064 \\
Personal motives & -0.032 & 0.076 & -1.118 & 0.264 \\
Academic motives & -0.083 & 0.195 & -2.894 & 0.004 \\
Migratory motives & -0.012 & 0.028 & -0.413 & 0.680 \\
\hline
\end{tabular}

Table 5. T-test for Equality of Means: motives for studying abroad per type of registration

\begin{tabular}{lllll}
\hline & \multicolumn{3}{l}{$\begin{array}{l}\text { Averages for } \\
\text { standardized values }\end{array}$} & $\begin{array}{l}\text { t-test for Equality of } \\
\text { Means }\end{array}$ \\
\cline { 2 - 5 } & Regular & Mobility & $\mathbf{t}$ & $\mathbf{p}$ \\
\hline Economic motives & 0.118 & -0.272 & 4.095 & 0.000 \\
Social motives & -0.210 & 0.485 & -8.754 & 0.000 \\
Personal motives & -0.029 & 0.066 & -0.981 & 0.327 \\
Academic motives & 0.018 & -0.042 & 0.650 & 0.516 \\
Migratory motives & 0.037 & -0.086 & 1.278 & 0.202 \\
\hline
\end{tabular}


slightly more present in the Groningen international students.

In academic motives, there is a significant difference between the two samples, with prominence of the importance of this factor for Groningen students. In the items of academic reasons, the non-existence of the field of study in the country of origin stands out, which indicates that the countries of origin of Groningen students, student issuing countries, do not have a solid higher education network, or, at least, are not sufficiently attractive for this target audience (Bhandari \& Blumenthal, 2011).

The t-test for difference in means in table 5 was also used to understand the differences between the two types of registration. There are differences $($ sig<0.05) for regular and mobility students for studying abroad related to economic and social motives. Personal, academic and migration motives do not present significant differences.
The economic reasons register values below average for students in mobility programs and above average for regular students. Looking carefully the items composing economic reasons (Raise their income in the future; Valorisation of a foreign diploma in the country of origin; New perspectives of employability; Assure a higher social status; Contribute for the economic development of their country), demand time to be achieved, only possible for regular students.

Social reasons (Experience living in a different country; Craving for travelling; Establish new friendships; Spirit of adventure) are reachable in a more reduced time frame, so they adjust to students spending a semester or two abroad, in mobility programs, presenting values considerably above average.

In the specific set of items composing the differentiating factors of regular and mobility students. It is possible to observe a prominence of the items analysed by the t-test

Table 6. City attractiveness factors

\begin{tabular}{|c|c|c|c|c|}
\hline & $\begin{array}{l}\text { Factor } \\
\text { loading }\end{array}$ & $\begin{array}{l}\text { Cronbach's } \\
\text { Alpha }\end{array}$ & Eigenvalue & $\begin{array}{l}\text { Variance } \\
\text { explained }\end{array}$ \\
\hline FACTOR 1 : Entertainment & & 0.892 & 8.310 & $41.55 \%$ \\
\hline Cultural offer & 0.661 & & & \\
\hline Night entertainment offer & 0.741 & & & \\
\hline City's touristic offer & 0.722 & & & \\
\hline Sport practice conditions & 0.573 & & & \\
\hline Leisure conditions & 0.706 & & & \\
\hline Preconceived image of the city & 0.707 & & & \\
\hline $\begin{array}{l}\text { Convenience in obtaining remote information on } \\
\text { the city }\end{array}$ & 0.640 & & & \\
\hline FACTOR 2: Easy Integration & & 0.816 & 1.725 & $8.62 \%$ \\
\hline Cost of living & 0.769 & & & \\
\hline Conditions for different goods consumption & 0.744 & & & \\
\hline Convenience of accommodation & 0.688 & & & \\
\hline City safety & 0.695 & & & \\
\hline Convenience to obtain visas & 0.593 & & & \\
\hline Having a university & 0.465 & & & \\
\hline FACTOR 3: Tourism & & 0.874 & 1.248 & $6.24 \%$ \\
\hline Climate & 0.757 & & & \\
\hline Location of the city in the country & 0.711 & & & \\
\hline Proximity to the sea & 0.785 & & & \\
\hline Gastronomy & 0.677 & & & \\
\hline $\begin{array}{l}\text { FACTOR 4: Work in the city and } \\
\text { Information on the city }\end{array}$ & & 0.602 & 1.198 & $5.99 \%$ \\
\hline Already know the city & 0.764 & & & \\
\hline Family or friends advice & 0.703 & & & \\
\hline Convenience in finding paid work & 0.459 & & & \\
\hline TOTAL variance explained & & & & $62.40 \%$ \\
\hline
\end{tabular}

Notes: a) coding: 1-Not important 5- Very important; b) Extraction Method: Principal Component Analysis. C) Rotation Method: Varimax with Kaiser Normalization. Rotation converged in 7 iterations. d) KMO Measure of Sampling Adequacy=0.918; Bartlett's test of Sphericity: $x 2=5360.59, d f=190, p=0.000$ 
for difference in means test, which stand out in economic reasons: raise their income in the future, contribute for the economic development of their country, and assure a higher social status, valorisation of a foreign diploma in the country of origin. Significant differences were identified in all items of social reasons: craving for travelling, experience of living in a different country, spirit of adventure, establish new friendships.

\section{Attractiveness of city and university}

To understand how each university attraction and city attraction variable was composed an exploratory analysis was carried out, with the Principal Component Analysis statistics technique, applied separately to the factors of city attractiveness in table 6 and to the factors of university attractiveness in table 7 , extracted with eigenvalues above one.

In the case of the city attractiveness factors, four components were registered $(\mathrm{KMO}=0.918$; Bartlett's test: $p<0.000$ ) and verified the internal reliability of these. The most important factor, by the value of the communalities, is Work in the city and Information on the city.

In the case of the attractiveness factors of the university, five components were defined (KMO=0.908; Bartlett's test: $\mathrm{p}<0.000)$, also verifying internal reliability with Cronbach's Alpha. According to the value of communalities, the most important factor is Scientific production and Infrastructures.

Table 7. University attractiveness factors

\begin{tabular}{|c|c|c|c|c|}
\hline ( & $\begin{array}{l}\text { Factor } \\
\text { loading }\end{array}$ & $\begin{array}{l}\text { Cronbach's } \\
\text { Alpha }\end{array}$ & Eigenvalue & $\begin{array}{l}\text { Variance } \\
\text { explained }\end{array}$ \\
\hline $\begin{array}{l}\text { FACTOR 1: Scientific Production and } \\
\text { Infrastructures }\end{array}$ & & 0.903 & 9.399 & $39.16 \%$ \\
\hline $\begin{array}{l}\text { Scientific production of a group } \\
\text { Global scientific production }\end{array}$ & $\begin{array}{l}0.866 \\
0.859\end{array}$ & & & \\
\hline One teacher's Scientific production & 0.837 & & & \\
\hline Promotion of scientific events & 0.719 & & & \\
\hline Quality of the teaching staff & 0.622 & & & \\
\hline Position on university rankings & 0.472 & & & \\
\hline Teaching infrastructures & 0.445 & & & \\
\hline FACTOR 2: Access to resources & & 0.863 & 2.059 & $8.58 \%$ \\
\hline Promotion of cultural events & 0.801 & & & \\
\hline Academic life & 0.799 & & & \\
\hline Internationalisation level & 0.666 & & & \\
\hline Student support services & 0.610 & & & \\
\hline Conditions for sport practice & 0.562 & & & \\
\hline Information available online & 0.548 & & & \\
\hline Offer of language courses & 0.524 & & & \\
\hline FACTOR 3: Costs and employ-ability & & 0.772 & 1.575 & $6.56 \%$ \\
\hline Convenience of university accommodation & 0.751 & & & \\
\hline Tuition fees & 0.738 & & & \\
\hline Location in the country & 0.705 & & & \\
\hline Employability for graduates & 0.542 & & & \\
\hline FACTOR 4: Accreditation & & 0.709 & 1.462 & $6.09 \%$ \\
\hline $\begin{array}{l}\text { Convenience of recognition of diploma in the } \\
\text { country of origin }\end{array}$ & 0.662 & & & \\
\hline Obtaining a degree in a specific field & 0.656 & & & \\
\hline Programmes offer & 0.536 & & & \\
\hline Perspective of obtaining good grades & 0.536 & & & \\
\hline FACTOR 5: Language & & 0.709 & 1.088 & $4.53 \%$ \\
\hline Assessment in English & 0.902 & & & \\
\hline Programmes in English. & 0.895 & & & \\
\hline TOTAL variance explained & & & & $64.92 \%$ \\
\hline
\end{tabular}

Notes: a) coding: 1-Not important 5- Very important; b) Extraction Method: Principal Component Analysis; c) Rotation Method: Varimax with Kaiser Normalization. Rotation converged in 6 iterations; d) KMO Measure of Sampling Adequacy=0.908; Bartlett's test of Sphericity: $x 2=7269.32, d f=276, p=0.000$ 


\section{Global indexes of attractiveness}

This study also aimed to know which aspect attracted the international students the most, the institution or the city. Based on the city and university attractiveness factors components recorded as new variables, the global indexes of attractiveness of the city and university were created, through a new Principal Component Analysis. The global index of city explains 25 per cent of the variance, the global index of university explains 20 per cent of the variance.

With both attractiveness indexes recorded, it is possible to compare the global index of city and the global index of university. When comparing the indexes averages, in terms of city attractiveness there is no significant differences between Coimbra and Groningen ( $p>0.05)$. Nevertheless, there are differences $(p<0.05)$ between the levels of attractiveness between the University of Coimbra and University of Groningen. Clearly, University of Groningen holds greater power of attractiveness to international students.

There is no significant difference between the cities that allows us to assess which detains the greater power of attractiveness for students. However, in terms of institution, the global index of attractiveness for Groningen is higher. It is also understood from the results, that the global index of attractiveness of the city of Coimbra is higher than the global index of attractiveness of the UC. On the contrary, in the Netherlands, the global indexes of attractiveness are positive, with RUG positioned ahead the city's index. The mystique of the city of Coimbra certainly has in its university one of its components, however, the institution, per se, is not so strong in attracting students. RUG, in terms of student attraction, has reached a level of success that surpasses the city.

The empirical data confirms the idea that the attractiveness factors of the university and the city vary according to their position in the world system. The city of Coimbra holds greater attractiveness than the University, contrarily to Groningen, where the University attracts more international students. Between the cities, there is no significant difference that allows us to assess which detains the greater power of attractiveness for students. However, in terms of institution, the global index of attractiveness for University of Groningen is higher.

\section{Discussion}

The paper attempts to answer the starting point: What predisposes foreign students to attend a university located in a European middle-sized city, in a country different from the one of their permanent residence? In this context, this paper analysed the student reasons that allows us to confirm if the priority is given to education or to tourism. These two groups appear as sociological differentiators, students do not focus exclusively on one of the poles, but show different trends that can be explained either as "study first", or as "tourism first". The regular international students focused in "study firs" giving priority to economical motives. The mobility international students focused in "tourism first" giving priority to social motives.

A pattern of decisions for choosing an institution appeared. Beginning with the desire to depart, which implicitly always carries a little mixture of desire for freedom and adventure. After this decision, the need for choosing the host country emerges. The host country's choice will be influenced by the student's idea of the country, as well as by the information that it is possible to get remotely. Therefore, it is possible to observe that the central countries of the world, with more influence in terms of image and marketing, get to the student faster. On the other hand, these countries hold major consulate networks in the semi-peripheral and peripheral countries, which helps with the legal and administrative procedures required for mobility. At this stage, the target image of a country influences their choice (Verbik \& Lasanowski, 2007).

After deciding the geographical area, it is necessary to specify the choice, that is, the student should choose the city and the university. As some studies suggest, this decision comes nuanced, this means that the city and university, although they have different attraction indicators, have elements that combine in this choice. Thus, it is difficult to highlight a priori which is the most influential factor. Sometimes the logic will apply to one or 
the other of these spheres, but both are equated in parallel in what concerns univer(ci)ty (Llewellyn-Smith \& McCabe, 2008; Glover, 2011 and Adams, 2011).

Another theme that stands out from the results are the main problems of academic mobility. They are identical to the problems found in the Middle Ages: travelling and accommodation. Despite the fact, that now we have more students and more institutions, for the student who wants to study abroad the problems remains the same: how to travel and where to stay. These two vectors are fundamentally connected with costs that determine the students' choices. Academic goals are and will always be important, but emerge many times conditioned by those factors. The students' reasons for studying abroad were hence grouped in the following five great clusters: economic, personal, migratory, social and academic.

Regarding students' origin, the neighbouring effect is felt on the mobility schemes. Coimbra receives a great number of Spanish, and Groningen a great number of Germans, which mirrors the same scale of the world system. It is possible to observe a prevalence of excolonies students, from Angola, Cape Verde and Brazil, in Coimbra, and from Indonesia in Groningen, thus contributing for the analytical typologies already conveying these ideas.

Deepening the reasons for studying abroad, the search for education abroad, looking for a supplement of school capital and degree legitimation, reflects social stratification. Only with an economic and social support network can a student afford to study abroad. The international students themselves have become transnational, that is, they may acquire diplomas abroad in more than one institution and this perspective marks a new stage for the educational tourism (Bhandari \& Blumenthal, 2011; Barron, Baum \& Conway, 2007; Altbach, 2013).

In this way, following the mobilities analysed by Urry (2007), emerging transnational communities of students, not in the sense of having a hybrid international student with two poles, one of origin and another of destination.
The hybrid character has gone further and reached a sense of transnationalisation. Today, it is easier to find examples of students that studied in different countries, in different study cycles, which leads us to the similarity of brain circulation "more accurately describe the increasing multidirectional nature of international flow and the growing awareness that such mobility patterns or exchanges are mutually beneficial for sending and receiving countries, albeit in varying ways" (Bhandari \& Blumenthal, 2011, p. 16). According to the European Commission data (2014), the number of students enjoying a mobility period is increasingly bigger, and part of these students continue their study cycles in a regular situation in other countries, other than their country of origin. In some countries like Germany, mobility has been integrated as a mandatory skill for students on their study cycles. Mobility programmes assume several goals and nuances.

In a political vision of academic mobility, the universities hold a major role as political decision-makers, not unique, as they coexist with other regulating axis from the State and the market, but they are definitely paramount in the increase of educational tourism, catalysts of student mobility (Chen, 2017b; Falcone, 2017). International students are perceived as a reserve and solution for European population ageing and for the sharp decrease of State budget for universities. Similarly, to replacement migration, a notion used by the United Nations in 2000, to characterise the migrations of labour replacement, the international student is comparable to a replacement student, a solution for the decline of national students.

This world movement of students implies very interesting economic value for several countries, which turns educational tourism into a market segment, explored and to be explored by the central hosting countries of this product and emerging in the semi-peripheral countries. As observed, these added-values emerge interconnected.

\section{Contribution}

The results of this research can contribute to a deeper understanding of the motivational 
factors for the worldwide movement of students. The empirical data will allow educational and touristic stakeholders to establish new strategies to attract more students, as has reinforced by Heung \& Leong: "In order to cater for this emerging market, modifications to existing tourism products and new product developments are necessary. The travel characteristics of university students are different from other groups, so tailor-made tours can be provided for them" (Heung \& Leong, 2006, p. 90).

This paper also aimed to contribute to the knowledge of educational tourism. There are few studies on this subject especially through the comparative model of statistical data. The motivation for the study resides on the renewed character of the subject matter, on the emergence of new actors, on the scarcity of studies in the field, especially in Europe, and more specifically on the data comparative model, taking in consideration the political context of the countries, based on worldsystem theory. This study shows universities the motivating factors for flow of international students, regular and in mobility, allowing these institutions to promote student recruitment policies. The major highlight of the present study is the comparison between international student populations from the University of Coimbra and from the University of Groningen. The compared conclusions always bring added value to research, not only for the opposition between the data and the theoretical model, but also for the comparison between empirical data collected based on a common protocol, which allows to advocate for the good methodological accuracy.

The results intended to reinforce the idea of an existing typified social context that predisposes international students to undertake a study period outside their country of permanent residence. It allowed exploring the student's predisposition from the beginning of his departure decision to the moment of integration in the host institution and how he does it. The questionnaire survey was validated and could be used for deeper investigation. The study contributes to a greater understanding of the theoretical framework of educational tourism, as it reinforces the explanation of the dichotomy of study first or tourism first.

\section{Limitations}

This paper has a number of limitations. First, the comparison was with two European universities, one located in central Europe and one in the south and should also include countries from North and East European Countries. Second, the size of the cities chosen is another limitation, the comparison was with two medium size cities and should include different size cities. The methodological assumptions were the right ones for comparative studies, but they limited the extrapolations to different types of cities and universities, especially outside Europe.

\section{Future research directions}

The results are important landmarks for new research on academic mobility, namely the integration of students in host universities, the level of academic success and the integration of students in the cities. The study should continue with the comparison with countries outside the European Union. Further studies must use samples from Nordic and East universities in different cultural settings. The comparison with other countries, outside of Europe, namely the ones that have the mark of receivers, like Australia and the United States of America will be important.

Acknowledgements: This work was supported by FEDER funds through the Operational Programme Competitiveness FactorsCOMPETE and national funds by FCTFoundation for Science and Technology Portugal- under the project PTDC / IVC-PEC / 5049/2012, Brain Drain and Academic Mobility from Portugal to Europe, coordinated by Rui Adelino Machado Gomes.

\section{References}

Altbach, P. (2013). The world is not flat: the brain drain and higher education in the 21st century. In Anna Glass (Ed.). The state of higher education 2013. OECD Higher Education Center, 103-107.

Barron, P., Baum, T. \& Conway, F. (2007). Learning, living and working experiences of international postgraduate students at a Scottish university. Journal of Hospitality and Tourism Management, 14 (2), 85-101.

Bhandari, R. \& Blumenthal, P. (2011). Global Student Mobility and the Twenty-First 
Century Silk Road: National Trends and New Directions. In R. Bhandari \& $P$. Blumenthal (Ed.) (2011). International Students and Global Mobility in Higher Education. New York: Palgrave Macmillan, 1-24.

Black, T. R. (1999). Doing quantitative research in the social sciences: in an integrated approach to research design, measurement and statistics. London: Sage Publications.

Bauman, Z. (1998). Globalization: the human consequences. United Kingdom: Polity Press.

Carvalho, H. (2004). Análise Multivariada de Dados Qualitativos- Utilização da HOMALS com SPSS. Lisboa: Edições Silabo.

Chao, C., Hegarty, N., Angelidis, J. \& Lu, V. (2017). Chinese students' motivation for studying in the United States. Journal of International Students, 7 (2), 246-256.

Chen, J. (2017a). Three Levels of Push-Pull Dynamics Among Chinese International Students' Decision to Study Abroad in the Canadian Context. Journal of International Students, 7 (1), 113-135.

Chen, Q. (2017b). Globalization and Translational Academic Mobility: the experiences of Chinese academic returnees. Singapore: Springer Higher Education Press.

Deardorff, D., Wit, H. \& Heyl, J. (2012). Bridges to the future: the global landscape of international higher education. In $D$. Deardorff, H. de Wit, J. Heyl \& T. Adams (Eds) (2012). The SAGE Handbook of International Higher Education. United States of America: Sage Publications, 457-486.

Eder, J., Smith, W. \& Pitts, R. (2010). Exploring factors influencing student study abroad destination choice. Journal of Teaching in Travel \& Tourism, 10 (3), 232-250.

European Commission. (2014). Erasmus + The EU programme for Education, Training, Youth and Sport 2014-2020. European Commission. URL: http://ec.europa.eu/pro grammes/erasmus-plus/documents /erasmus-plus-in-detail en.pdf

Falcone, S. (2017). International student recruitment: trends and challenges.
Journal of International Students, 7 (2), 257-269.

Gallarza, M.G., Saura, I. \& Garcia, H. (2002). Destination image: towards a conceptual framework. Annals of Tourism Research, 29 (1), 56-78.

Gardiner, S., King, B. \& Wilkins, H. (2013). The travel behaviours of international students. Journal of Vacation Marketing, 19 (4), 287-299.

Giddens, A. (1999). Runaway world. How globalization is reshaping our lives. London: Profile Books.

Glover, P. (2011). International students: linking education and travel. Journal of Travel \& Tourism Marketing, 28, 180-195.

Gomes, R.M. (2005). O governo da educação em Portugal. Coimbra: Imprensa da Universidade de Coimbra.

Hattie, J., Marsh, H., Neill, J. \& Richards, G. (1997). Adventure Education and Outward Bound: Out-of-class Experiences that Make a Lasting Difference. Review of Educational Research, 67, 43-87.

Heung, V. \& Leong, J. (2006). Travel demand and behaviour of university students in Hong Kong. Asia Pacific Journal of Tourism Research, 11 (1), 81-94.

Jaramillo I. C. \& Wit, H. (2011). Student Mobility Trends in Latin America. In R. Bhandari \& P. Blumenthal (Eds.) (2011). International Students and Global Mobility in Higher Education. New York: Palgrave Macmillan, 129-142.

Kline, P. (2002). An easy guide to factor analysis. London: Routledge.

Llewellyn-Smith, C. \& McCabe, V. (2008). What is the attraction for Exchange students: the host destination or host university? Empirical evidence from a study of an Australian University. International Journal of Tourism Research, 10, 593-607.

Mazzarol, T. \& Soutar, G. (2001). "Push-pull" factors influencing international student destination choice. The International Journal of Educational Management, 16 (2), 82- 90.

Michael, I., Armstrong, A. \& King, B. (2003). The travel behavior of international students: the relationship between studying abroad and their choice of tourism destinations. Journal of vacation marketing, 10 (1), 57-66. 
Moreira, L. \& Gomes, R. (2017). Os perfis dos estudantes em mobilidade no sistema mundo. Paper presented at the Congresso Ensino Superior Pós Bolonha: tempo de balanço tempo de mudança, September 2015, Coimbra.

OECD (2018). Education at a Glance 2018. Paris: OECD Publishing.

Ritchie, B. W. (2003). Managing educational tourism. Clevedon, UK: Channel View Publications.

Santos, B. S. (2005). A universidade do século $X X I$ : para uma reforma democrática $e$ emancipatória da Universidade. 2.ed. São Paulo: Cortez Editora.

Spata, A. (2005). Métodos de pesquisa: ciências do comportamento e diversidade humana. Rio de Janeiro: LTC editora.
Tarrant, M., Stoner, L., Borrie, W., Kyle, G. \& Moore, R. (2011). Educational travel and global citizenship. Journal of Leisure Research, 43 (3), 403-426.

UNESCO (2009). Global education digest 2009: Comparing education statistics around the world. Canada: UNESCO Institute for statistics.

Urry, J. (2007). Mobilities. New York: Polity Press.

Verbik, L. \& Lasanowski, V. (2007). International student mobility: patterns and trends. United Kingdom: The Observatory on borderless higher education.

Wallerstein, I. (1991). Geopolitics and Geoculture. Cambridge: Cambridge University Press. 